\title{
CURRENT PHARMACOLOGICAL STATUS OF CARDIOPROTECTIVE PLANTS AGAINST ISOPROTERENOL INDUCED MYOCARDIAL INFARCTION
}

\author{
SYEDA NISHAT FATHIMA ${ }^{1,2 *}$, VASUDEVA MURTHY S \\ ${ }^{1}$ Department of Pharmacy, Shri Jagdishprasad Jhabarmal Tibrewala University, Jhunjhunu, Rajasthan, India. ${ }^{2}$ Department of \\ Pharmacology, Jayamukhi College of Pharmacy, Warangal, Telangana, India. Email: Syeda.nishat.fathima85@gmail.com
}

Received: 08 December 2017, Revised and Accepted: 06 January 2018

\section{ABSTRACT}

Objective: Cardiovascular diseases are the major cause of morbidity and mortality in the modern era. Myocardial infarction is a condition where there is a significant decrease or block in the blood (oxygen) supply to the part of heart, leading to degeneration of a portion of the myocardium which triggers a cascade of cellular, inflammatory and biochemical events, leading eventually to the irreversible death (necrosis) of heart muscle cells. Various therapeutic interventions, including lifestyle modification, pharmacological treatment options, and surgical techniques are available. The present review focus on the plants that have been evaluated for cardioprotective activity against isoproterenol-induced myocardial infarction.

Method: The current status of Cardioprotective plants was obtained from a literature search of electronic databases such as Google Scholar, Pubmed and Scopus up to 2017 for publications on medicinal plants used against isoproterenol-induced myocardial infarction. Isoproterenol, Isoprenaline, myocardial infarction, cardioprotective were used as keywords for the searching.

Result: A total of 117 different plant parts and their extracts have till now been published to possess cardioprotection against isoproterenol-induced myocardial infarction. Isoproterenol a beta-adrenergic receptors agonist causes severe stress in myocardium resulting in the infarct-like lesion and produced cardiotoxic effects by elevating the levels of cardiac biomarkers and causing changes in ECG. Plant-based medicines with their antioxidant, antiapoptotic, antihyperlipidemic, platelet antiaggregatory, anti-lipid peroxidation property provide substantial evidence for the management of Ischemia.

Conclusion: This review, therefore, provides a useful resource to enable a thorough assessment of the profile of plants that have cardioprotective activity against isoproterenol-induced myocardial infarction.

Keywords: Isoproterenol; Myocardial infarction; Cardioprotective

(c) 2018 The Authors. Published by Innovare Academic Sciences Pvt Ltd. This is an open access article under the CC BY license (http://creativecommons. org/licenses/by/4. 0/) DOI: http://dx.doi.org/10.22159/ajpcr.2018.v11i4.24158

\section{INTRODUCTION}

Cardiovascular diseases are the foremost cause of morbidity and mortality globally; more people die annually from cardiovascular diseases than from any other cause. An estimated 17.7 million people died from cardiovascular diseases in 2015, representing 31\% of all global deaths. Of these deaths, an estimated 7.4 million were due to coronary heart disease and 6.7 million were due to stroke. Over three-quarters of cardiovascular disease, deaths take place in low- and middle-income countries. There are 32.4 million myocardial infarctions and strokes cases worldwide every year [1]. Myocardial infarction (i.e., heart attack) is defined pathologically as the irreversible death (necrosis) of myocardial cells secondary to prolonged lack of oxygen supply (ischemia). In concept, the imbalance between oxygen delivery and myocardial oxygen demand can be corrected by decreasing oxygen demand or by increasing delivery (by increasing coronary flow) [2]. Oxygen demand can be reduced by decreasing cardiac exertion or, according to recent studies, by shifting myocardial metabolism to substrates that involve less oxygen per unit of adenosine triphosphate (ATP) produced. Among the pharmacological agents used in the treatment of infarction are nitrovasodilators, $\beta$-adrenergic receptor antagonists, calcium channel antagonists, and antiplatelet agents. All approved agents improve the balance of myocardial oxygen supply and demand, increasing supply by dilating the coronary vasculature or decreasing demand by decreasing cardiac work [3]. The progress in the management of myocardial infarction is a result of several major trends, including improvements in risk stratification, more widespread use of an invasive strategy, implementation of care delivery systems prioritizing immediate revascularization through percutaneous coronary intervention (or fibrinolysis), advances in antiplatelet agents and anticoagulants, and greater use of secondary prevention strategies such as statins [4]

Isoprenaline or isoproterenol [1-(3, 4-dihydroxyphenyl)-2isopropylamino ethanol hydrochloride] is a synthetic catecholamine used for the treatment of bradycardia, heart block, and rarely for asthma. It is a non-selective $\beta$-adrenoreceptor agonist and Trace amine-associated receptor 1 agonist that is the isopropylaminomethyl analog of epinephrine, which is an important controller of myocardial contractility and metabolism, thus serving as the key element of a standard model for the study of potentially beneficial effects of numerous drugs on cardiac function [5]. Isoproterenol induces cardiac necrosis by several mechanisms, including increased oxygen consumption, functional hypoxia and ischemia, coronary insufficiency, poor oxygen utilization, increased calcium overload and accumulation, altered myocardial cell metabolism, increased myocardial cyclic adenosine monophosphate levels, decreased level of high-energy phosphate stores, deranged electrolyte milieu, altered membrane permeability, intracellular acidosis, oxidative stress, and increased levels of lipid peroxides [6]. Isoproterenol induces myocardial infarction by causing alterations in hematological, biochemical, oxidative stress markers, and histopathological parameters [7].

A plethora of herbal medicines is employed routinely by patients to manage and/or treat chronic cardiovascular conditions and related complications. Interestingly, more than 2000 plants have been documented to be used in traditional systems of medicine, and some of these are providing comprehensive relief to the people suffering 
from cardiovascular diseases and related complications, especially hyperlipidemia and ischemic heart disease among others [8]. The present review endeavors to overview up-to-date information on plants that have been proved to have a cardioprotective effect against isoproterenol-induced myocardial infarction.

\section{THE PHARMACOLOGICAL STATUS OF SOME CARDIOPROTECTIVE PLANTS AGAINST ISOPROTERENOL-INDUCED MYOCARDIAL INFARCTION}

1. Acalypha indica leaf methanolic extract restored inflammatory marker (lactate dehydrogenase), cardiac markers (C-reactive protein, troponin-T, and creatine kinase-muscle/brain [MB]), and lipid peroxidase activity to normal levels in isoproterenol-induced myocardial infarction in rats [9].

2. Hydroalcoholic extract of Achyranthes aspera restored the isoproterenol-induced myocardial necrosis altered serum levels of cardiac injury markers (creatine kinase-MB, lactate dehydrogenase, alkaline phosphatase, aspartate transaminase and alanine transaminase, and total proteins), antioxidant defense status (catalase, superoxide dismutase, glutathione, and lipid hydroperoxide) in the heart to the normal [10].

3. The administration of water extract of rhizomes of Acorus gramineus in male pigs possesses significant cardioprotective potential against isoproterenol-induced myocardial infarction as it significantly attenuated increased cardiac injury markers, such as cardiac troponin $\mathrm{T}$, tumor necrosis factor (TNF)- $\alpha$, and myeloperoxidase activity, and cardiac marker enzymes, and prevented the depletion of antioxidant parameters [11].

4. The treatment of Male Albino rats with Baobab fruit pulp (Adansonia digitata) showed significant cardioprotective activity by bringing all the parameters such as cardiac markers (creatine kinase MB, lactate dehydrogenase, and aspartate aminotransferase), some antioxidant enzymes, interleukin (IL)-1 $\beta$, monocyte chemoattractant protein-1, myeloperoxidase, collagen- 1 , galectin- 3 , and serum corticosterone to near normal level in isoproterenol administered model rat [12].

5. Cardiopreventive effects of an aqueous Aegle marmelos leaf extract in isoproterenol-induced myocardial infarction in rats is by significantly decreasing creatine kinase and lactate dehydrogenase and by increasing the heart rate. A. marmelos pretreatment increased the activity of $\mathrm{Na}+-\mathrm{K}+$ ATPase and decreased the activity of $\mathrm{Ca}+2$ ATPase in the heart and aorta simultaneously along with decreasing the levels of cholesterol and triglycerides and increasing phospholipids in the heart and aorta [13].

6. The aqueous extract of Allium cepa bulb significantly recovered the altered parameters (troponin-I, creatine kinase-MB, glutamatepyruvate transaminase, heart rate, $\mathrm{R}-\mathrm{R}$ interval, and oxidative stress markers) in isoprenaline-induced myocardial injury in Wistar albino rats [14].

7. The garlic (Allium sativum) oil elicited a significant cardioprotective activity by lowering the levels of serum marker enzymes (aspartate aminotransferase, alanine aminotransferase, lactate dehydrogenase, and creatine phosphokinase) and lipid peroxidation and elevated the levels of glutathione. The cardioprotective effects of garlic oil in isoproterenol-induced oxidative damage may be due to an augmentation of the endogenous antioxidants and inhibition of lipid peroxidation of the membrane [15].

8. The ethanolic extract of Alstonia scholaris (Family, Apocynaceae) significantly decreased the serum biomarkers creatine kinase-MB and lactate dehydrogenase and restoration of biochemical and histopathological alterations of heart tissue [16].

9. Amaranthus viridis oral treatment for 45 days elicited a significant cardioprotective activity by lowering the levels of serum marker enzymes, cardiac troponin, glutathione disulfide and lipid peroxidation, and elevated the levels of antioxidant enzymes and glutathione [17].

10. The hydroalcoholic extract of Ananas comosus possess cardioprotective activity against isoproterenol-induced myocardial infarction in rats by decreasing the elevated the cholesterol, low-density lipoprotein, very low-density lipoprotein, triglycerides, alanine aminotransferase and aspartate aminotransferase levels and increasing high-density lipoprotein and total protein in plasma along with reducing infracted zone with inflammatory cells, lipid droplets, myocardial necrosis, and vacuolization of myofibrils [18].

11. The ethanol leaf extract of Andrographis paniculata exhibited the cardioprotective effect in rats showing potent antioxidant properties (increased antioxidant enzymes such as superoxide dismutase, glutathione peroxidase, glutathione S-transferase, and glutathione, and reduced oxidative stress markers such as Myeloperoxidase) as well as improving the hemodynamic changes in the rats [19].

12. Pretreatment with the aqueous leaf extract of Artemisia afra prevented the elevation of serum marker enzymes, namely, lactate dehydrogenase, aspartate transaminase, alanine transaminase, and ALP (Alkaline phosphatase) in isoproterenol-induced myocardial injured rats. The extract also attenuated lipid peroxidation in the heart and improved the imbalance in glutathione reductase, glutathione peroxides, superoxide dismutase, glutathione, and lipid profile caused by isoproterenol [20].

13. Cardiac hemodynamics, heart coefficient and marker enzymes in serum showed that Astragali radix prevented isoproterenol-induced myocardial damage. A. radix also improved the antioxidant status by decreasing the lipid peroxidative product Myeloperoxidase and increasing the activity of the antioxidant enzyme superoxide dismutase. The observed depressions in sarcoplasmic reticulum calcium ATPase messenger ribonucleic acid and protein expression as well as ser(16)-phosphorylated phospholamban protein expression in isoproterenol-treated rats were attenuated by A. radix treatment [21].

14. The hydroalcoholic Averrhoa carambola fruit extract maintains near normal levels of cardiac biomarker enzymes (cardiac troponin-T, creatinine kinase, and lactate dehydrogenase) and antioxidant enzymes (glutathione, MPO, catalase, and superoxide dismutase). The infarcted hearts treated with extract showed a reduction in necrosis, infiltration of leukocyte and inflammation conferring its cardioprotective effect [22].

15. Aqueous leaf extract of Azadirachta indica exhibits cardioprotective effect by significantly restoring hemodynamic (mean arterial blood pressure, systolic arterial blood pressure, diastolic arterial blood pressure, and heart rate), biochemical cardiac marker enzymes (lactate dehydrogenase and serum glutamate oxaloacetic transaminase [SGOT]), and histopathological parameters in isoprenaline-induced myocardial necrosis in rats [23].

16. The ethanolic extract of Azolla microphylla alleviates myocardial damage of isoproterenol which significantly diminution in cardiac antioxidant enzyme activities, increased lipid peroxidation and alteration in cardiac marker enzymes apart from increasing levels of serum lipid profiles and pro-inflammatory cytokines (IL-6 and IL-8) accompanied with a significant reduction in the anti-inflammatory cytokine levels (IL-10). Treated rats improved energy metabolism of cardiac mitochondria by upregulating and downregulating expressions of Bcl-2 and Bax/iNOS proteins [24].

17. The standardized hydroalcoholic lyophilized extract of Bacopa monnieri produced maximum cardioprotection as evidenced by significant restoration of endogenous antioxidants (superoxide dismutase, catalase, glutathione peroxidase, and reduced glutathione), myocyte-specific injury markers (myocardial lactate dehydrogenase and creatine kinase-MB isoenzyme), and decrease in lipid peroxidation marker Myeloperoxidase (MPO) [25].

18. Dose-dependent cardioprotection was observed in the ethanolic extract of Bixa orellana as it significantly decreased the serum cardiac marker enzymes, lipid, and MPO levels as well as increased the enzymatic and non-enzymatic antioxidants [26].

19. Anthocyanin-rich red Brassica oleracea L. cabbage extract alleviated isoproterenol-induced myocardial infarction by attenuating heart: Body weight ratio, decreasing circulating levels of creatine kinaseMB, improving levels of enzymatic antioxidants (superoxide dismutase and catalase), and favorable modulations of apoptotic markers (bax and bcl-2) [27]. 
20. The methanol extract of Buddleja asiatica, ameliorated the biochemical (creatine kinase-myoglobin, SGOT, lactate dehydrogenase, serum glutamate pyruvate transaminase [SGPT], and total protein) and antioxidant parameters (catalase, superoxide dismutase, reduced glutathione, glutathione peroxidase, glutathione reductase, and MPO) levels significantly in isoproterenol-induced oxidative stress thereby offering significant cardioprotection [28].

21. The alcoholic and aqueous extract of Caesalpinia crista Linn (Caesalpiniaceae) attenuated the heart damage induced by isoproterenol was indicated by elevated levels of the marker enzymes such as creatine kinase-isoenzyme, lactate dehydrogenase, SGOT, and SGPT in serum with increased lipid peroxide and reduced glutathione content in heart homogenates. Histopathological observation also revealed marked protection by the extract in myocardial necrotic damage [29].

22. Marigold extract Calendula officinalis augmented the myocardial antioxidant enzyme level, preserved histoarchitecture and improved cardiac performance by changing marker level following isoproterenol administration [30].

23. Black tea extract (Camellia sinensis) reduced the levels of glutathione, thiobarbituric acid reactive substances, superoxide dismutase, catalase, lactate dehydrogenase, and SGOT isoproterenol-induced myocardial infarction in Wistar Albino rats as well as protected the heart by reducing in the infarct size [31].

Protective effect of Camellia sinensis floral extract was examined against isoproterenol-induced myocardial infarction in male albino rats. The oral administration of aqueous extract of $C$. auriculata afforded protection against isoproterenol-induced alterations in cholesterol, low-density lipoprotein, high-density lipoprotein, triglyceride, protein, aspartate aminotransferase, alanine aminotransferase, lactate dehydrogenase, catalase, and glutathione peroxidase. The protective effect was further supported by the histological observations. The results clearly demonstrate that $C$. auriculata flowers have a potent cardioprotective effect [32].

25. Centella asiatica showed a significant cardioprotective activity by lowering the levels of serum marker enzymes (lactate dehydrogenase and creatine kinase) and lipid peroxidation (MPO) as well as elevated the levels of antioxidant enzymes (reduced glutathione, superoxide dismutase, and catalase) against myocardial infarction induced by isoproterenol [33].

26. Ethanolic extract of root of Chonemorpha fragrans strongly protected the myocardium against isoproterenol-induced infarction and elicits cardioprotective effects which could be related to antioxidant activities. Animals treated with root extract of $C$. fragrans showed a significant decrease in triglycerides, aspartate aminotransferase, ALP, antioxidant enzymes, namely, superoxide dismutase, lipid hydroperoxide, and increase in high-density lipoprotein cholesterol [34].

27. Isoproterenol-induced cardiac dysfunction, which was characterized by a significant increase in the heart weight/body weight ratio, serum calcineurin, nitric oxide, lactate dehydrogenase, and thiobarbituric acid reactive substance levels, as well as a significant decrease in serum-reduced glutathione, cardiac glutathione peroxidase, glutathione reductase, and glutathione-S-transferase levels, which were significantly improved by Cissampelos pareira root extract treatment [35].

28. The ethanol extracts of Citrus macroptera peel and pulp attenuated the isoproterenol-induced severe myocardial injuries associated with oxidative stress, as confirmed by elevated lipid peroxidation and decreased cellular reduced glutathione and antiperoxidative enzymes, including glutathione peroxidase, glutathione reductase, and glutathione-S-transferase. Pretreatment with C. macroptera peel and pulp extracts, significantly improved biochemical parameters, i.e., cardiac Troponin I, cardiac marker enzymes, lipid profile, and oxidative stress markers [36].

29. Ethanolic extract of Citrus medica L. brought increased lipid peroxidation and alteration of myocyte-injury specific marker enzymes, levels of plasma cholesterol, triglycerides, low-density lipoprotein cholesterol, and very low-density lipoprotein cholesterol parameters toward a normal level which were increased in isoproterenol-induced cardiac dysfunction [37].

30. The level of marker enzyme in serum lactate dehydrogenase, creatine kinase-MB fraction, aspartate transaminase, alanine transaminase, Troponin-I were significantly decreased in rats pretreated with Coleus forskohlii. The disruptions of several subcellular elements including myonecrosis, myophagocytosis and lymphocytic infiltration, edema, loss of myofibrils, swelling of mitochondria, vacuolization of the cytoplasm, formation of lysosomal bodies and dilation of the sarcotubule and dilation of the sarcotubular system brought by isoproterenol were restored to normal with extract treatment [38].

31. Commiphora mukul was commonly known as guggul significantly reversed the decrease in myocardial antioxidants; superoxide dismutase, catalase, glutathione peroxidase, reduced glutathione, along with enhanced lipid peroxidation; MPO levels in heart against isoprenaline-induced myocardial necrosis in rats. In addition, to improving myocardial antioxidant status, C. mukul also prevented the leakage of myocyte injury marker enzymes creatine phosphokinase-MB and lactate dehydrogenase from the heart. Further, histopathological examination showed the lessening of necrosis, edema, and inflammation following C. mukul pretreatment [39].

32. Cordia sebestena to leaf extract significantly decreased the elevated levels of cardiac marker enzymes such as creatine kinase-MB, aspartate aminotransferase, alanine aminotransferase, lactate dehydrogenase and ALP in serum, and serum lipid profiles such as high-density lipoprotein, low-density lipoprotein, very low-density lipoprotein, triglycerides, and cholesterol in isoproterenol-induced myocardial infarction in rats [40].

33. Coriandrum sativum significantly resisted showed increased lipid hydroperoxide, decreased levels of endogenous antioxidants and ATPases in the cardiac tissue together with increased plasma lipids and markers of cardiac damage in showed increased lipid hydroperoxide, decreased levels of endogenous antioxidants and ATPases in the cardiac tissue together with increased plasma lipids and markers of cardiac damage. The methanolic extract of $C$. sativum is able to prevent myocardial infarction by inhibiting myofibrillar damage [41].

34. Saffron (dried stigmas of Crocus sativus L.), exerts cardioprotection in isoproterenol-induced myocardial damage by preserving hemodynamics and left ventricular functions, maintaining structural integrity and augmenting antioxidant status [42].

35. Methanolic extract of Croton sparsiflorus showed the significant cardioprotective effect by lowering the serum levels of various biochemical parameters such as creatine phosphokinase, lactate dehydrogenase, and transaminases in the isoproterenol-induced cardiotoxicity model [43].

36. The ethanolic extract of Cucumis trigonus fruit decrease in serum enzyme levels and the electrocardiogram (ECG) (increase heart rate, reduced R-wave amplitude, and ST-segment elevation) changes brought to the near normal values which were significantly increased when treated with isoproterenol. Animals treated with $C$. trigonus demonstrated marked improvement in isoproterenol-induced alterations such as vacuolar changes, edema, capillary dilatation, and leukocyte infiltration [44].

37. Hydroalcoholic extract of Curcuma longa rhizome significantly reversed myonecrosis caused by isoproterenol through augmentation of endogenous antioxidants (glutathione, thiobarbituric acid reactive substances, catalase, glutathione peroxidase, and superoxide dismutase), maintenance of the myocardial antioxidant status and significant restoration of the altered hemodynamic parameters (systolic, diastolic and mean arterial pressure, heart rate, left ventricular end-diastolic pressure, and left ventricular peak positive $(+) \mathrm{dP} / \mathrm{dt}$ (rate of pressure development) and negative $(-) \mathrm{dP} / \mathrm{dt}$ (rate of pressure decline)) [45].

38. The levels of cardiac enzymes such as aspartate transaminase, alanine transaminase, creatinine kinase-myoglobulin, lactate dehydrogenase, and the gold marker Troponin-I altered by isoproterenol were found 
to be restored significantly by ethanolic extract of Cyperus rotundus on isoprenaline-induced myocardial infarction [46].

39. The levels $\mathrm{Na}+\mathrm{K}+\mathrm{ATPase}, \mathrm{Mg} 2+\mathrm{ATPase}$, and Ca2+ATPase in heart; serum aspartate transaminase, alanine transaminase, lipid peroxidase, and lactate dehydrogenase levels and cardiac total protein and lipid peroxidase, and lactate dehydrogenase altered by isoproterenol were restored significantly by the administration of the Daucus carota extract [47].

40. Desmodium gangeticum root extract pretreatment reverted back the altered levels of heart weight, body weight, heart weight / body weight ratio, percent of hypertrophy, collagen accumulation, activities of matrix metalloproteinase- 2 and-9, superoxide dismutase and catalase enzymes, and the level of an oxidative stress marker, lipid peroxide to near normal in isoproterenol-induced left ventricular cardiac hypertrophy [48].

41. Isoproterenol-induced rats when pretreated with the flavonoid-rich fraction of Dioscorea bulbifera amelioration of the lipid peroxidation and enhancement the antioxidant status as evidenced by the increase in the reduced glutathione content and the activity of antioxidant enzymes was observed. Moreover, the tricarboxylic acid cycle enzymes such isocitrate dehydrogenase, succinate dehydrogenase, malate dehydrogenase, and $\alpha$-ketoglutarate dehydrogenase, which were found decreased in the isoproterenol-induced rats showed enhanced activity in D. bulbifera pretreated rats. The activity of $\mathrm{NADH}$ dehydrogenase and cytochrome-C-oxidase the enzymes, which transfer the electron in the electron transport chain was also increased significantly in D. bulbifera pretreated rats thereby suggesting its cardioprotective effect [49].

42. Cardamom (Elettaria cardamomum) treatment reversed the isoproterenol-induced myocardial injury which caused cardiac dysfunction demonstrated by declined arterial pressure indices, heart rate, contractility, and relaxation along with increased preload; decrease in endogenous antioxidants, superoxide dismutase, catalase, glutathione peroxidase, depletion of cardiomyocytes enzymes, creatine kinase-MB, lactate dehydrogenase, and increase in lipid peroxidation. All these changes in cardiac and left ventricular function as well as endogenous antioxidants, lipid peroxidation, and myocyte enzymes were ameliorated when pretreated with cardamom [50].

43. Aqueous extract of fruits of Embelia ribes showed substantial cardioprotective property in a rat model having acute myocardial infarction, induced by isoproterenol by significantly increasing the heart rate, systolic blood pressure, decreasing levels of serum lactate dehydrogenase, serum creatine kinase and myocardial lipid peroxides and significantly decreasing the myocardial endogenous antioxidants (glutathione, superoxide dismutase, and catalase) levels along with reversing the myocardial injury caused by isoproterenol [51].

44. Emblica officinalis exhibited significant cardioprotective activity by reversing the isoproterenol-induced cardiotoxicity in rats by increasing mean arterial pressure, heart rate, contractility, and relaxation along with decreased left ventricular end diastolic pressure, increased antioxidant enzymes, superoxide dismutase, catalase and glutathione peroxidase and myocyte-injury-specific marker enzymes, creatine phosphokinase-MB, and lactate dehydrogenase in heart along with restoration of reduced glutathione and decreasing thiobarbituric acid reactive substances beside histopathological salvage of myocardium. The cardioprotective potential of $E$. officinalis is attributed to its potent antioxidant and free radical scavenging activity [52].

45. The hydroalcoholic extract of fruit pulp of Eugenia jambolana showed significant cardiopreventive effects on isoproterenol-induced myocardial damage in rats by decreasing oxidative stress parameters, markers of inflammation, cardiac damage markers, and apoptotic markers along with improving cardiac architecture [53].

46. Hydroethanolic Euphorbia hirta leaf extract was found to diminish the effect of isoproterenol on the levels of total cholesterol, triglycerides, and low-density lipoprotein with a parallel rise in the level of highdensity lipoprotein. The necrosis of myofibrils with inflammatory mononuclear collections and edema caused by isoproterenol was reversed by the administration of extract [54].

47. Evolvulus alsinoides administration causes myocardial adaptation by augmenting endogenous antioxidants and protects rat hearts from oxidative stress associated with isoproterenol-induced myocardial injury [55].

48. The aqueous extract of Garcinia indica fruit rinds showed a significant reduction in creatine kinase $\mathrm{MB}$ fraction, creatine kinase-N-acetylcysteine, lactate dehydrogenase levels, and increase in superoxide dismutase and catalase levels when compared to isoproterenol-induced myocardial damage rats. The cardioprotective effect was also confirmed by histopathology of hearts which showed less necrosis in extract treated rats [56].

49. Garcinia pedunculata aqueous fruit extract significantly ameliorated the effect of isoprenaline by reducing the activity of creatine kinaseMB and the levels of ALP, SGPT, respectively. A severe necrotic lesion in the myocardial tissue which was seen with isoprenaline administration was brought to nearly normal cytoarchitecture [57].

50. The methanolic extract of Gardenia gummifera root protected the serum levels of cardiac marker enzymes (lactate dehydrogenase, aspartate aminotransferase, and creatine kinase-MB), serum iron and iron binding capacity, uric acid, and ceruloplasmin; antioxidants (catalase, glutathione peroxidase, glutathione reductase, glutathioneS-transferase, and reduced glutathione) and lipid peroxidation (MPO) levels/parameters to fall from the normal levels [58].

51. Ginkgo biloba phytosomes and Ocimum sanctum extract significant restored isoproterenol depleted activities and levels of endogenous antioxidants (superoxide dismutase, catalase, glutathione peroxidase, glutathione reductase, and glutathione) heart homogenate. A significant decrease in isoproterenol-induced serum marker enzyme (aspartate aminotransferase, lactate dehydrogenase, and creatine phosphokinase) elevations and a significant attenuation of the isoproterenol elevated myocardial lipid peroxidation marker MPO demonstrates significant cardiac protection of $G$. biloba phytosomes and 0 . sanctum extract [59].

52. Administration of plant extract of Hybanthus enneaspermus reduced the oxidative stress by decreased lipid peroxidation and reduced glutathione and also normalized the levels of cardiac marker enzymes such as creatine kinase, lactate dehydrogenase; SGOT, SGPT, and cardiac specify protein Troponin I in myocardial infarction induced by isoproterenol. H. enneaspermus treated animals showed a lesser degree of cellular infiltration in histopathological studies [60].

53. The hydroalcoholic leaf extract of Indigofera tinctoria Linn. showed decrease in the levels of serum marker enzymes by increase in cardiac total protein; and increased antioxidant levels such as superoxide dismutase, reduced glutathione, and glutathione peroxidase with decreased thiobarbituric acid reactive substances levels in both serum and heart tissue, thereby possessing cardioprotective effect by ameliorating the myocardial infarction induced by isoproterenol [61].

54. Inula racemosa root hydroalcoholic extract improved cardiac function by increasing the heart rate, mean arterial pressure, contractility, and relaxation along with decreasing left ventricular end diastolic pressure and also significantly restored the reduced form of glutathione and endogenous antioxidant enzymes superoxide dismutase, catalase, and glutathione peroxidase from the heart, which were depleted after isoproterenol administration. It protects the heart from isoproterenol-induced myocardial injury by reducing oxidative stress and modulating hemodynamic and ventricular functions of the heart [62].

55. The cardioprotective role of Justicia tranquebareinsis leaf extract on isoproterenol-induced myocardial infarction in Wistar albino rats is due to decrease in levels of cholesterol, triglycerides, phospholipids, and lipoproteins as well as myocardial marker enzymes [63].

56. The standardized aqueous and $80 \%$ ethanol extracts of Labisia pumila var. alata showed significant protective effects as pretreated rats showed a significant decrease in cardiac enzyme activities, i.e., cardiac Troponin I, creatine kinase MB isoenzyme, lactate dehydrogenase, alanine transaminase, and aspartate transaminase 
and rises in the activity of oxidase enzymes, i.e., glutathione peroxide, catalase, and superoxide dismutase were observed. Histopathological examination showed an improvement in membrane cell integrity in pretreated rats [64].

57. Lagenaria siceraria fruit juice showed protective effect against altered biochemical changes such as significant increase in the levels of serum uric acid, tissue $\mathrm{Na}+$ and $\mathrm{Ca}++$ ions, and membrane-bound $\mathrm{Ca}+2$-ATPase activity; decrease in the levels of serum protein, tissue $\mathrm{K}+$ ion, Vitamin $\mathrm{E}$ level, and the activities of $\mathrm{Na}+\mathrm{K}+-\mathrm{ATPa} e$ and $\mathrm{mg}+2$-ATPase in isoproterenol-induced myocardial infarction [65].

58. Lavandula angustifolia essential oil amended ECG pattern by suppressing ST-segment elevation and increasing R-amplitude. Oil treatment decreased heart to body weight ratio and the elevated myeloperoxidase and MPO in heart tissues suggesting its protective role of myocardium against isoproterenol-induced myocardial infarction [66].

59. The of ethanolic fruit extract of Limonia acidissima significantly decreased the cardiac marker enzyme (creatinine phosphokinase and lactate dehydrogenase) and increased the antioxidant enzymes (superoxide dismutase and catalase) signifying it is cardioprotective effect against the acute cardiac damage induced by isoproterenol in rats [67].

60. The flaxseed oil (Linum usitatissimum) showed an important inhibition of angiotensin-converting enzyme. It reversed the isoproterenol-induced changes such as ST-segment elevation, increase in the serum levels of Troponin $\mathrm{T}$ and cardiac injury markers (creatine kinase-MB, lactate dehydrogenase, ALP, aspartate transaminase, and alanine transaminase). Flaxseed oil also preserved the structural and functional integrity of the myocardial membrane, as evident from the reduction in the activities of cardiac dysfunction markers [68].

61. The methanolic extract of Marrubium vulgare significantly amended the ECG changes (ST-segment elevation and suppressed R-amplitude) by isoproterenol injection. The extract strongly increased left ventricular contractility and decreased the left ventricular enddiastolic pressure, and suppressed markedly the elevation of MPO levels both in serum and in myocardium suggesting that the protective effect could be related to antioxidant activities [69].

62. The ethanolic extract of Medicago sativa stem pretreatment reversed the lipid profile level, liver marker enzymes (SGPT and SGOT), cardiac marker enzymes (creatine kinase-MB and lactate dehydrogenase), and antioxidants (superoxide dismutase, catalase, glutathione peroxidase, and lipid peroxidase) to near normal than isoproterenol induced rats [70].

63. The polysaccharide extract of Momordica charantia pretreatment significantly inhibited increases in heart weight, the heart-weight to body-weight ratio, and infarction size, and ameliorated the increased serum levels of aspartate transaminase, creatine kinase, lactate dehydrogenase, total cholesterol, triglycerides, very lowdensity lipoprotein cholesterol, low-density lipoprotein cholesterol, and high-density lipoprotein cholesterol. In addition, M. charantia enhanced the activity of superoxide dismutase, catalase, and nonprotein sulfhydryls, and decreased the level of lipid peroxidation. It downregulated the expression of pro-inflammatory cytokines (TNF alpha, IL-6, and IL-10), inflammatory markers (nitric oxide, myeloperoxidase, and inducible nitric oxide synthase), and apoptotic markers (caspase- 3 and Bax), and upregulated Bcl-2 expression. Pretreatment with $M$. charantia reduced myonecrosis, edema, and inflammatory cell infiltration, and restored cardiomyocytes architecture. This myocardial protective effect of $M$. charantia against isoproterenol-induced myocardial infarction could be related to the enhancement of the antioxidant defense system through the nuclear factor kappa B pathways, and to anti-apoptosis through regulation of Bax, caspase-3, and Bcl-2 [71].

64. The pretreatment with ethanolic extract of Momordica cymbalaria prevented the elevation of serum marker enzymes, lactate dehydrogenase, creatinine kinase-MB fraction, aspartate transaminase, alanine transaminase, ALPs, and alterations in the oxidative stress markers such as lipid peroxidase activity, glutathione activity, catalase, and superoxide dismutase cause by isoproterenol myocardial infarction in rats [72].

65. Lyophilized hydroalcoholic extract of Moringa oleifera leaf exhibited significant cardioprotective effect by reducing effects on isoproterenol-induced hemodynamic perturbations. Chronic M. oleifera treatment resulted in significantly favorable modulation of the biochemical enzymes and prevented the deleterious histopathological and ultrastructural perturbations caused by isoproterenol. The cardioprotective effect may be attributed to its antioxidant, antiperoxidative, and myocardial preservative properties [73].

66. The ethyl acetate soluble fraction of Morus alba L. significantly reduced ST segment, heart rate, arterial pressure, pressure rate index, heart weight, lactate dehydrogenase, creatine kinase-MB, and SGOT, whereas the levels of antioxidant enzymes were increased significantly. It reduced the pressor response to catecholamines (isoprenaline) and also showed protection from hypertrophy and degenerative changes in myocardial muscles [74].

67. The aqueous extract of Muntingia calabura L. significantly prevented isoproterenol-induced elevation in the levels of the diagnostic marker enzymes (aspartate transaminase and alanine transaminase, lactate dehydrogenase, and creatine phosphokinase). The cardioprotective effect of the M. calabura leaf extract is probably related to its ability to strengthen the myocardial membrane by its membrane-stabilizing action [75].

68. Nelumbo nucifera leaf extract prevents free radical-mediated myocardial damage and thereby eliminating the acute fatal complications by protecting the membrane damage against isoproterenol-induced infarction. $N$. nucifera leaf extract pretreatment also shows the inhibition of necrosis and reduced inflammation in isoproterenol-induced rats. The free radical scavenging, antioxidant, lipid lowering, and membrane stabilizing properties of leaf extract could be responsible for these effects on histology of the myocardium [76]

69. Nepeta deflersiana ethanolic extract pretreatment prevented the depletion of endogenous antioxidants (catalase, superoxide dismutase, non-protein thiol, and nitric oxide) and myocyte injury marker enzymes and inhibited lipid peroxidation MPO. It also downregulated the expression of pro-inflammatory cytokines (TNF $\alpha$, IL-6, and IL-10) and apoptotic markers (caspase-3 and Bax) and upregulated the anti-apoptotic protein Bcl2. Extract reduced myonecrosis, edema, and infiltration of inflammatory cells and restored the architecture of cardiomyocytes thereby displaying strong antioxidant, cardioprotective, anti-inflammatory, and anti-apoptotic potential against myocardial damage induced by isoproterenol [77].

70. The hydroethanolic extract of Nerium oleander Linn. prevented the elevation of marker enzymes such as lactate dehydrogenase, $\gamma$-glutamyl transferase, creatine kinase (creatine kinase-MB and creatine phosphokinase), aspartate aminotransferase, alanine aminotransferase, and ALP in plasma when administered before isoproterenol challenge. It significantly attenuated the lipid peroxidation by maintaining the levels of enzymatic (superoxide dismutase and glutathione peroxidase) and non-enzymatic antioxidants (reduced glutathione and nitrite), which was also confirmed histologically [78].

71. Along with very low-density lipoprotein, triglycerides, cholesterol, and free fatty acids, the levels of marker enzymes in serum such as aspartate aminotransferase, alanine aminotransferase, lactate dehydrogenase, creatine kinase, and tissue lipid profile of triglycerides, cholesterol, and free fatty acids were significantly decreased, whereas the levels of creatine kinase-MB and high-density lipoprotein, low-density lipoprotein in serum and tissue lipid profile of phospholipids were significantly increased in rats pretreated with Nigella sativa seeds [79].

72. The ethanolic extract of aerial parts of Ocimum basilicum (basil) significantly suppressed the elevation of MPO levels, suppressed ST-segment elevation and severe myocardial necrosis and fibrosis with a sharp reduction in left ventricular contractility and a marked 
increase in left ventricular end-diastolic pressure induced by isoproterenol [80].

73. Pretreatment of hydroalcoholic extract of Ocimum canum significantly reduced glutathione, aspartate aminotransferase, alanine aminotransferase, creatine phosphokinase, Troponin T, catalase, superoxide dismutase, and lactate dehydrogenase levels and inhibited the lipid peroxidation as observed by the reduced thiobarbituric acid reactive substances levels demonstrate cardioprotective effect against isoproterenol [81].

74. Egyptian sweet marjoram (Origanum majorana) leaf powder and marjoram leaf aqueous extract significantly reduced erythrocytosis, granulocytosis, thrombocytosis, shortened clotting time, decrease in relative heart weight, myocardial oxidative stress and the leakage of heart enzymes (creatine phosphokinase, creatine phosphokinaseMB isoenzyme, lactate dehydrogenase, and aminotransferase) in isoproterenol treated rats through reactivating non-enzymatic (reduced glutathione) and enzymatic (catalase, glutathione peroxidase, glutathione S-transferase, and superoxide dismutase) antioxidant defense system and inhibiting the production of nitric oxide and lipid peroxidation in heart tissues [82].

75. Aqueous extract of Oxalis corniculata exhibits protective potential against isoproterenol-induced myocardial infarction in rats by decreasing in the activity of cardiac injury marker enzymes such as creatine phosphokinase and lactate dehydrogenase; lipogenic enzyme, glucose-6-phosphate dehydrogenase, and lipid peroxidation products (thiobarbituric acid reactive substances and conjugated dienes) and the concentration of serum lipids. O. corniculata exhibits significant antioxidant and radical scavenging activity against 2,2-diphenyl picrylhydrazyl, superoxide, and nitric oxide radicals and was found to be protecting the myocardium against ischemic insult by its antioxidative and antihyperlipidemic activities [83].

76. Red ginseng (Panax ginseng) has been shown to possess various ginsenosides that possess cardioprotective potential against isoproterenol-induced myocardial infarction by significantly attenuating isoproterenol-induced cardiac dysfunctions by improving ventricular hemodynamic functions and reducing ST segment and QRS complex intervals along with increasing myocardial injury parameters such as antioxidants [84].

77. The ethanolic leaf extract of Pandanus odoratissimus significantly decreased the cardiac marker enzyme creatinine phosphokinase and lactate dehydrogenase and increased the levels of creatinine phosphokinase and lactate dehydrogenase of superoxide dismutase and catalase exhibiting cardioprotective activity against isoproterenol-induced cardiac damage [85].

78. The hydroalcoholic extract of stem bark of Parkia biglobosa ameliorated positively biochemical alterations, prevented oxidative stress and histological and morphological changes induced by isoproterenol [86].

79. Ajwa, a special variety of Saudi Arabian dates (Phoenix dactylifera L.) is a rich source of nutrients, fibers, and bioactive molecules. While previous studies have shown the therapeutic value of dates phytoconstituents in liver and kidney diseases, etc., its cardioprotective potential remains elusive. We, therefore, investigated the cardioprotective effect of lyophilized Ajwa extract ex vivo as well as in vivo. Oral administration of extract prevented the depletion of endogenous antioxidants (catalase, superoxide dismutase, nonprotein thiol, and nitric oxide) and myocyte injury marker enzymes, and inhibited lipid peroxidation (MPO, myeloperoxidase). As well as downregulated the expressions of pro-inflammatory cytokines (IL-6, IL-10, and TNF $\alpha$ ) and apoptotic markers (caspase-3 and Bax), and upregulated the anti-apoptotic protein Bcl2. Extract pretreatment reduced myonecrosis, edema, and infiltration of inflammatory cells and restored the cardiomyocytes architecture [87]

80. The ethanol extract of Picrorhiza kurroa rhizomes and roots significantly prevented the isoproterenol-induced myocardial infarction by modulating the changed lipid metabolism in serum and heart tissue to normal [88].

81. Piper betle extract favorably modulated hemodynamic (systolic, diastolic, and mean arterial pressure) and ventricular function parameters apart from restoring superoxide dismutase, catalase, glutathione peroxidase, reduced glutathione, and myocyte injury marker enzymes; creatine phosphokinase-MB isoenzyme and lactate dehydrogenase along with reducing the leakage of creatine phosphokinase-MB isoenzyme and lactate dehydrogenase and decreasing lipid peroxidation in the heart against isoproterenolinduced myocardial infarction in rats [89].

82. The methanolic extract of Piper longum pretreatment days significantly prevents the damage induced by isoproterenol by decreasing levels of serum myocardial markers creatine kinaseMB and lactate dehydrogenase and histopathological examination evinced by decreased vascular and fatty degeneration, granular disintegration and hyaline necrosis of muscle fibers [90].

83. The methanol extract of Polygonum glabrum showed greater cardioprotection by restoring the cardiac marker enzymes (creatine kinase, lactate dehydrogenase, SGOT, SGPT, and total protein) and attenuated the level of plasma lipid profiles plasma total cholesterol, triglycerides, high-density lipoprotein, low-density lipoprotein, and very low-density lipoprotein along with an increase in high-density lipoprotein. In addition, level of myocardial antioxidants significantly increased along with a reduction in the content of MPO against isoproterenol induced myocardial necrosis [91].

84. Pretreatment with the hydroalcoholic leaf extract of Pongamia pinnata significantly attenuated the transaminases (aspartate transaminase and alanine transaminase), lactate dehydrogenase and creatine phosphokinase activities thereby offering protection in experimental cardiotoxicity induced by isoproterenol [92].

85. Punica granatum seed juice extract attenuates cardiotoxic effects of isoproterenol by reversing thrombus formation, contraction band necrosis and inflammation of myocardium along with restoration of heart rate, pressure rate index, and ECG values to normal. A significant increase in the levels of superoxide dismutase and catalase activity and increased vascular reactivity to various catecholamines and a significant decrease in the levels of cardiac marker enzymeslactate dehydrogenase and creatine kinase indicate a substantial therapeutic value in the prophylactic treatment of myocardial infarction [93].

86. Alcoholic extract of the stem part of Rhus tripartita male genotype significantly mitigated isoproterenol triggered upregulation of cardiac-specific markers of injury creatine kinase and lactate dehydrogenase. Extract treatment significantly attenuated the isoproterenol-induced increase in myocardial MPO, serum cholesterol, and triglycerides as well alterations in serum lipoproteins and decrease in non-protein sulfhydryl in cardiac tissue. Pretreatment with extract enhanced the survival fraction of cardiac cells exposed to oxidative stress [94].

87. Rhodobryum roseum elicited a significant cardioprotective effect by augmentation of the endogenous antioxidants and inhibition of lipid peroxidation of the membranes. Significant myocardial necrosis, increase serum marker enzymes (lactate dehydrogenase, glutamate oxaloacetic transaminase, and creatine kinase) by isoproterenol were reversed by pretreatment with ethanolic extract of $R$. roseum [95].

88. Pretreatment with ethanolic extract of Rhododendron arboretum prevented the increase in serum and tissue lipid peroxidation, serum cardiac marker enzymes such as lactate dehydrogenase aspartate transaminase and alanine transaminase and the decrease in both enzymatic and non-enzymatic antioxidants in isoproterenol-treated rats [96].

89. Polysaccharide from Salvia miltiorrhiza showed the extensive cardioprotective effect on isoproterenol-induced myocardial infarction in rats. Pretreatment with polysaccharide for 30 days significantly increased the body weight, decreased the heart weight, attenuated the serum levels of creatine kinase, creatine phosphokinase-MB, dehydrogenase, alkaline phosphate, aspartate transaminase, alanine transaminase, total cholesterol, triglyceride, and low-density lipoprotein cholesterol, along with the increased concentration of high-density lipoprotein cholesterol. In addition, it also enhanced myocardial superoxide dismutase, catalase, and glutathione peroxidase activities and elevated myocardial reduced 
glutathione level, along with a decrease in thiobarbituric acid reactive substances concentration. It produces a cardioprotective effect through enhancement of endogenous antioxidants and antihyperlipidemic activity [97].

90. The aqueous extract of root of Saussurea lappa produced significant dose-dependent cardioprotective activity against isoproterenolinduced myocardial injury by reversing the increased serum concentration of lactate dehydrogenase, creatinine kinase, and aspartate transaminase increased myocardial thiobarbituric acid reactive substances level and decreased myocardial glutathione level due to myocardial damage produced by isoproterenol [98].

91. Pretreatment with the ethanolic extract of fruits of Sechium edule significantly reduce the levels of serum transaminases, alkaline phosphates, lactate dehydrogenase, creatinine kinase, total cholesterol, triglycerides, low-density lipoprotein cholesterol, very low-density lipoprotein cholesterol, and increase the levels of highdensity lipoprotein cholesterol in isoproterenol-induced myocardial necrosis in rats [99].

92. Sida rhomboidea extract displays cardioprotective effect by decreasing heart weight, plasma lipid profile, plasma marker enzymes of cardiac damage, cardiac lipid peroxidation, $\mathrm{Ca}+2$ ATPase and significantly increasing plasma high-density lipoprotein, cardiac endogenous enzymatic and non-enzymatic antioxidants, Na+-K+ ATPase and Mg+2 ATPase against isoproterenol induced myocardial necrosis in rats [100].

93. The hydroalcoholic extract of Semecarpus anacardium nuts ameliorates the myocardial damage induced by isoproterenol by elevation in superoxide dismutase activity with a simultaneous increase in catalase and thiobarbituric acid reactive substances activity along with a change in biomarkers and antioxidants levels to normal [101].

94. Lycopene isolated from Solanum lycopersicum significantly prevented the isoproterenol-induced ECG, hemodynamic (i.e., systolic, diastolic, and mean arterial pressure), biochemical (C-reactive protein, myeloperoxidase, nitrite levels, and caspase- 3 protease activity), electrolytes ( $\mathrm{Na}+\mathrm{K}+$, and $\mathrm{Ca} 2+$ ), and apoptotic (increase in DNA fragmentation) changes thereby exhibiting significant cardioprotective effect [102].

95. Hydroalcoholic extract of Solanum nigrum Linn. reduced the creatine kinase-MB, lactate dehydrogenase, SGOT, SGPT, cholesterol, triglycerides, and Troponin-T to normal values. Treatment with extract significantly reduced the effects of isoproterenol-induced myocardial infarction by attenuating superoxide dismutase, catalase, and glutathione levels [103]

96. Ethanolic extract of Solanum surattense was found to be most effective in the reduction of cardiac biomarkers such as creatine kinase-MB and lactate dehydrogenase and restoration of membrane-bound $\mathrm{Na}+$ / $\mathrm{K}+\mathrm{ATPase}$, tissue antioxidant enzymes such as superoxide dismutase, catalase and glutathione, and histopathological alterations against isoproterenol-induced biochemical alterations [104].

97. Prior treatment with a hydroethanolic extract of Solanum torvum significantly decreased the levels of cholesterol, triglycerides, low-density lipoprotein, and increased the levels of high-density lipoprotein in isoproterenol-induced myocardial infarcted rats [105].

98. The hydroethanolic leaf extract of Solanum xanthocarpum possesses potent cardioprotective activity as it significantly decreases in the levels of total cholesterol, triglycerides, low-density lipoprotein, and an increase in high-density lipoprotein in isoproterenol-induced rats [106].

99. The $70 \%$ ethanolic extract of bark of Spathodea campanulata P. Beauv protected myocardium from isoproterenol-induced myocardial functional and structural injury through normalization levels of diagnostic marker enzymes such as serum aspartate aminotransferase, alanine aminotransferase, lactate dehydrogenase, creatine phosphokinase, triglycerides, total cholesterol, low-density lipoproteins and high-density lipoproteins, and by restoring the glutathione and lipid peroxidation levels. The extract showed remarkable improvement of the cardiac architecture by reversing the focal lesions, fragmentation of muscle fibers and retrogressive lesions over the isoproterenol-treated groups [107].
100. Alterations to markers of myocardial injury and indices of antioxidant capacity by isoproterenol intoxication were significantly corrected on pretreatment with Spondias mombin. A significant decrease in the inflammatory index, serum lactate dehydrogenase activity and cholesterol level whereas increase in tissue catalase and superoxide dismutase activities, as well as glutathione level, was noted in extract treated group. Disruption in the structure of cardiac myofibrils by isoproterenol intoxication was reduced by treatment with S. mombin [108].

101. Aqueous fruit extract, alcoholic fruit extract, aqueous seed extract, and alcoholic seed extract of Tamarindus indica exhibited cardioprotective activity against isoproterenol hydrochlorideinduced myocardial infarction in rats by reversing the increase in serum marker enzymes, an increase in the percent infarction area increase in heart weight and a decrease in body weight along with the decrease in endogenous enzyme levels. Pretreatment and cotreatment with the various extracts decreased the heart rate, ST segment elevation, and QT interval, while an increased RR interval was observed against infract induced control [109].

102. The $70 \%$ ethanolic extract of Tecoma stans prevented fall in antioxidants such as lipid peroxidation, superoxide dismutase, reduced glutathione, and catalase and retarded elevation of cardiac damage markers such as alanine aminotransferase, aspartate aminotransferase, lactate dehydrogenase, creatinine kinase, total cholesterol, triglycerides, low-density lipoproteins, and high-density lipoproteins in isoproterenol-treated rats, significantly [110].

103. The ethanol and aqueous extracts of Terminalia arjuna bark significantly restored the level of total cholesterol, triglyceride, low-density lipoprotein, high-density lipoprotein and myocardial and serum of lactate dehydrogenase, creatine kinase, and aspartate aminotransferases which were altered by isoproterenol induction [111].

104. Cardioprotective effect of ethanolic extract of Terminalia chebula fruits in isoproterenol-induced myocardial damage in rats is due to decrease in the level of lipid peroxides and myocardial marker enzymes in the serum and heart [112].

105. Ethanolic extract of Terminalia pallida fruits reversed the significant increase in total cholesterol, triglycerides, low-density lipoprotein cholesterol, and very low-density lipoprotein cholesterol, highdensity lipoprotein cholesterol, and MPO and a significant decrease in high-density lipoprotein-C, cardiac marker enzymes-creatine kinase, lactate dehydrogenase, alanine transaminase, aspartate transaminase and reduced antioxidants-catalase, glutathione peroxidase, sodium potassium, calcium, and magnesium ATPs caused by isoproterenol [113].

106. The ethanolic extract of Terminalia belerica extract has efficiently protected the myocardium against isoprenaline-induced myocardial infarction by ameliorating the enzymes creatine kinase, lactate dehydrogenase, alanine aminotransferase, and aspartate aminotransferase to normal [114].

107. The methanolic extract of Tinospora cordifolia significantly restored the altered levels of heart, heart weight/body weight ratio, and cardiac enzymes such as aspartate transaminase, alanine transaminase, creatinine kinase, lactate dehydrogenase, and Troponin-I in myocardial infarction caused by isoproterenol [115].

108. Hydroalcoholic lyophilized extracts of Tribulus terrestris upregulated heat shock protein 70; increased basal superoxide dismutase, catalase activity and caused a marked fall in basal thiobarbituric acid reactive substances levels. The significant augmentation of myocardial glutathione content and glutathione peroxidase activity following isoproterenol-induced myocardial injury fortified the cardioprotective activity of T. terrestris [116].

109. $70 \%$ ethanolic extract of Trichopus zeylanicus leaves offered cardioprotection by alterations and restoration of the cardiac markers such as aspartate aminotransferase, alanine aminotransferase, lactate dehydrogenase, and creatine phosphokinase to normal levels against isoproterenol-induced myocardial ischemia [117]. 
110. The ethanolic extract of Trigonella foenum-graecum significantly decreased blood glucose, bilirubin, total cholesterol, triglyceride and low-density lipoprotein level, myocardial lactate dehydrogenase, creatine kinase total, and creatine kinase-MB levels; and the high-density lipoprotein level was returned back to normal in isoproterenol-induced myocardial infarction. Marked myocytic necrosis with moderate infiltration of lymphocytes and macrophages was reversed by T. foenumgraecum pretreatment [118].

111. Ethanolic extract of Urtica parviflora reversed the effects of isoproterenol-induced myocardial infarction in rats by effectively controlling serum low-density lipoprotein levels and reducing cardiac complication by decreasing the levels of serum cholesterol, alanine transaminase, aspartate aminotransferase, ALP and increasing the levels of superoxide dismutase, catalase, and reduced glutathione [119].

112. The methanolic extract of Ventilago maderspatana pretreatment has shown cardioprotective activity significantly by reducing the concentration of cardiac injury marker enzymes (creatine kinase-MB, Lactate dehydrogenase, aspartate aminotransferase, alanine aminotransferase, and ALP) and serum lipids (total cholesterol levels, low-density lipoprotein, high-density lipoprotein, and triglycerides) against isoproterenol-induced myocardial infarction [120].

113. The prior administration of Vitex negundo leaf ethanolic extract is effective in minimizing all the deleterious and myocardial infarction related effects induced by isoproterenol, with its capacity to fortify the myocardial cell membrane and heart tissue architecture, and also by normalizing biochemical and molecular parameters such as cardiac marker enzymes (creatine kinase-heat specific, creatine kinase, lactate dehydrogenase and gamma glutamyl transferase, aspartate transaminase, and alanine transaminase), antioxidant enzymes (reduced glutathione, glutathione s-transferase, and glutathione peroxidase), and signaling molecules (p21 activated kinase 1 and nuclear factor-kB) [121].

114. Ethanolic extract of seeds of Vitis vinifera significantly prevented the isoproterenol-induced elevation in the levels of diagnostic marker enzymes (aspartate aminotransferase, alanine aminotransferase, and lactate dehydrogenase) and lipid peroxidation in plasma, indicating the cardioprotective activity [122].

115. Significant cardioprotective effects were observed on protein, urea, creatinine, serum lipid profile, cardiac marker enzymes, and antioxidants, when treated with hydroethanolic extract of Wedelia, Chinensis against isoproterenol-induced myocardial infarction in rat [123].

116. Withania somnifera leaf extract preserves the integrity of myocardial cell membrane by maintaining the activities of cardiac Troponin I levels and serum lipid profiles, as well as the activities of marker enzymes of isoproterenol-induced myocardial infarction. Cardioprotective activity may be due to antilipoperoxidative and antioxidant effects [124].

117. Gingerols and shogaols present in Zingiber officinale showed decrease in all the cardiac enzyme activities, i.e., cardiac Troponin I, creatine kinase-MB isoenzyme, lactate dehydrogenase, alanine transaminase, and aspartate transaminase against isoproterenolinduced myocardial infarction along with significant rises in the activity of glutathione peroxide, catalase, and superoxide dismutase apart from improvement in membrane cell integrity [125].

\section{REFERENCES}

1. Cardiovascular Diseases (CVDs). World Health Organization. Geneva: World Health Organization; 2017. Available from: http://www.who.int/ mediacentre/factsheets/fs317/en.

2. Silverstein DC, Kate H. Myocardial Infarction. Small Animal Critical Care Medicine. Ch. 41. St Louis, MO: Saunders; 2014. p. 174-6.

3. Laurence LB, Chabner BA, Knollmann BC, Chabner BA, Knollmann BC. Treatment of myocardial ischemia and hypertension. The Goodman and Gilman's Manual of Pharmacology and Therapeutics. 12th ed. Ch. 27. New York: McGraw-Hill Medical; 2014. p. 745-65.

4. Grant WR, Jeffrey ER, Christopher PC. Acute myocardial infarction.
Lancet 2017;389:197-210.

5. Kleinau G, Pratzka J, Nürnberg D, Grüters A, Führer-Sakel D, Krude H, et al. Differential modulation of Beta-adrenergic receptor signaling by trace amine-associated receptor 1 agonists. PLoS One 2011;6:E27073.

6. Rona G. Catecholamine cardiotoxicity. J Mol Cell Cardiol 1985;17:291-306.

7. Bhagat B, Sullivan JM, Fischer VW, Nadel EM, Dhalla NS. CAMP activity and isoproterenol-induced myocardial injury in rats. Recent Adv Stud Cardiac Struct Metab 1976;12:465-70.

8. Suroowan S, Mahomoodally F. Common phyto-remedies used against cardiovascular diseases and their potential to induce adverse events in cardiovascular patients. Clin Phytosci 2015;1:1.

9. Senthil MP, Ramprasath T, Selvam S. Cardioprotective role of Acalypha indica extract on isoproterenol induced myocardial infarction in rats. $\mathrm{J}$ Pharm Res 2011:4:2129-32.

10. Shaik E. Evaluation of cardioprotective effect of Achyranthes aspera on isoproterenol induced myocardial infarction in rats. Int J Pharm Biosci 2017;8:124-30.

11. Kim JH, Chung HS, Antonisamy P, Lee SR, Bae H. Cardioprotective effect of rhizomes of Acorus gramineus against isoproterenol-induced cardiac damage in pigs. Cardiovasc Toxicol 2014;14:183-92.

12. Ghoneim MA, Hassan AI, Mahmoud MG, Asker MS. Protective effect of Adansonia digitata against isoproterenol-induced myocardial injury in rats. Anim Biotechnol 2016;27:84-95.

13. Khanna P, Rawri RK, Asdaq SM, Nayeem N, Chakraborty M. Cardioprotective activity of methanolic extract of Aegle marmelos leaf extract against isoproterenol induced myocardial damage in rats. $\mathrm{J}$ Pharm Res 2010;9:35-8

14. Kharadi GB, Patel KJ, Purohit BM, Baxi SN, Tripathi CB. Evaluation of cardioprotective effect of aqueous extract of Allium cepa Linn. Bulb on isoprenaline-induced myocardial injury in Wistar albino rats. Res Pharm Sci 2016;11:419-27.

15. Senthilkumar GP, Moses MF, Sengottuvenlu S, Rajarajan T, Sarvanan G. Cardioprotective activity of garlic (Allium sativum) in isoproterenol induced rat myocardial necrosis: A biochemical and histoarchitectural evaluation. Int J Pharm Sci Nanotech 2010;2:779-84.

16. Pullaiah CP, Venkateswarlu M, Sridhar C, Susma R, Shivarami RY. Evaluation of cardio protective activity of ethanolic extract of Alstonia scholaris on isoproterenol induced myocardial infarction in rats. Int Res J Pharm 2013;4:112-6.

17. Saravanan G, Ponmurugan P, Sathiyavathi M, Vadivukkarasi S, Sengottuvelu S. Cardioprotective activity of Amaranthus viridis linn: Effect on serum marker enzymes, cardiac troponin and antioxidant system in experimental myocardial infarcted rats. Int $\mathrm{J}$ Cardiol 2013;165:494-8.

18. Priya S, Dharamveer P. Cardioprotective potential of hydro-alcoholic fruit extract of Ananas comosus against isoproterenol induced myocardial infraction in Wistar Albino rats. J Acute Dis 2014;3:228-34.

19. Adeolu AA, Bisi OA, Ademola AO, Temidayo OO, Momoh AY. Cardioprotective Effects of the ethanol leaf extract of Andrographis paniculata in isoproterenol-induced myocardial infarction in rats. FASEB J 2017;31:1070-12.

20. Sunmonu TO, Afolayan AJ. Protective effect of Artemisia afra jacq. on isoproterenol-induced myocardial injury in wistar rats. Food Chem Toxicol 2010;48:1969-72.

21. Xu XL, Ji H, Gu SY, Shao Q, Huang QJ, Cheng YP, et al. Cardioprotective effects of Astragali radix against isoproterenolinduced myocardial injury in rats and its possible mechanism. Phytother Res 2008;22:389-94.

22. Pitroda KD, Sachdeva PD. Evaluation of cardio protective effect of Averrhoa carambola fruit in isoproterenol induced myocardial infarction in rats. Int J Pharm Sci Res 2016;7:2845-51.

23. Peer PA, Trivedi PC, Nigade PB, Ghaisas MM, Deshpande AD. Cardioprotective effect of Azadirachta indica A. Juss. On isoprenaline induced myocardial infarction in rats. Int J Cardiol 2008;126:123-6.

24. Bhaskaran SK, Kannappan P. Protective effect of Azolla microphylla on biochemical, histopathological and molecular changes induced by isoproterenol in rats. Biomed Pharmacother 2017;89:473-81.

25. Nandave M, Ojha S, Sujata, J, Kumari S, Arya SD. Cardioprotective effect of Bacopa monneira against isoproterenol-induced myocardial necrosis in rats. Int J Pharmacol 2007;3:385-92

26. Kuppusamy A, Puliyath J, Muthusamy U, Thirumalaisamy S, Varadharajan S, Arumugam M. Cardioprotective activity of Bixa orellana L. On isoproterenol induced myocardial necrosis in rats. J Pharm Res 2012;5:1930-4

27. Jana S, Patel D, Patel S, Upadhyay K, Thadani J, Mandal R, et al. Anthocyanin rich extract of Brassica oleracea L. Alleviates 
experimentally induced myocardial infarction. PLoS One 2017;12:e182137.

28. Raja S, Ramya I. Cardioprotective effect of methanol extract of Buddleja asiatica on isoproterenol induced myocardial necrosis in rats. Der Pharmacia Lett 2017;9:207-16.

29. Kumar SR, Sharma RK. Cardio protective effect of Caesalpinia crista Linn. on isoproterenol induced myocardial necrosis in rats. Int J Res Pharm Sci 2013;3:119-30.

30. Sidharth M, Rajesh D, Ravinder K, Sanjeev K. Experimental investigation of marigold extract: Modulates isoproterenol induced myocardial ischemia in rats. Innov Pharm Pharmacother 2016;3:743-57.

31. Razieh AM, Akhtar M, Atefeh AM, Abul KN. Evaluation of cardioprotective effects of Camellia sinensis on isoproterenol induced myocardial infarction. Int J Pharm Sci Res 2013;4:1056-63.

32. Manimegalai S, Venkatalakshmi P. Cardioprotective effect of Camellia sinensis Linn., petal extract on isoproterenol induced myocardial infarction in male albino rats. Int J Pharm Sci Res 2012;3:848-52.

33. Vinay K, Vivek B, Nagarajan K, Lalit M, Umakant B. Protective effects of Centella asiatica against isoproterenol-induced myocardial infarction in rats: Biochemical, mitochondrial and histological findings. J Phytopharmacol 2015;4:80-6.

34. Mathew G, Lincy J, Sujith K, Minu M. Evaluation of cardioprotective activity of Chonemorpha fragrans alston root extract. Int J Res Pharm Pharm Sci 2017;2:92-5.

35. Singh BK, Pillai KK, Kohli K, Haque SE. Effect of Cissampelos pareira root extract on isoproterenol-induced cardiac dysfunction. J Nat Med 2013;67:51-60.

36. Paul S, Das S, Tanvir EM, Hossen MS, Saha M, Afroz R, et al. Protective effects of ethanolic peel and pulp extracts of Citrus macroptera fruit against isoproterenol-induced myocardial infarction in rats. Biomed Pharmacother 2017;94:256-64.

37. Al-Yahya MA, Mothana RA,Al-Said MS, El-Tahir KE,Al-Sohaibani M, Rafatullah S. Citrus medica "Otroj": Attenuates oxidative stress and cardiac dysrhythmia in isoproterenol-induced cardiomyopathy in rats. Nutrients 2013;5:4269-83.

38. Farogh A, Siddiqui HH, Tarique M, Ritesh KS, Ahmad N. Evaluation of cardioprotective effect of Coleus forskohlii against isoprenaline induced myocardial infarction in rats. Indian J Pharm Biol Res 2014;2:17-25.

39. Ojha S, Bhatia J, Arora S, Golechha M, Kumari S, Arya DS, et al. Cardioprotective effects of Commiphora mukul against isoprenalineinduced cardiotoxicity: A biochemical and histopathological evaluation. J Environ Biol 2011:32:731-8.

40. Lakshmi M, Kumar B, Naresh PB. Evaluation of cardioprotective activity of ethanolic extract of Cordia sebestinato against myocardial infarction. Int J Chem Pharm Sci 2017;5:1-6.

41. Patel DK, Desai SN, Gandhi HP, Devkar RV, Ramachandran AV. Cardio protective effect of Coriandrum sativum L. On isoproterenol induced myocardial necrosis in rats. Food Chem Toxicol 2012;50:3120-5.

42. Mehdizadeh R, Parizadeh MR, Khooei AR, Mehri S, Hosseinzadeh H. Cardioprotective effect of saffron extract and safranal in isoproterenolinduced myocardial infarction in wistar rats. Iran J Basic Med Sci 2013;16:56-63.

43. Abi BG, Mohamed SA, Sivakumar V, Jaya SR. Cardioprotective activity of methanolic extract of Croton sparciflorus on isoproterenol induced myocardial infarcted wistar albino rats. J Med Plants Stud 2014;2:1-8

44. Thippeswamy BS, Thakker SP, Tubachi S, Kalyani GA, Netra MK, Patil U, et al. Cardioprotective effect of Cucumis trigonus Roxb on isoproterenol-induced myocardial infarction in rat. Am J Pharmacol Toxicol 2009;4:29-37.

45. Mohanty IR, Arya DS, Gupta SK. Dietary Curcuma longa protects myocardium against isoproterenol induced hemodynamic, biochemical and histopathological alternations in rats. Int J Appl Res Nat Prod 2009; $1: 19-28$

46. Khwaja S, Mahmood T, Siddiqui HH. Effect of ethanolic extract of Cyperus rotundus $\mathrm{L}$. against isoprenaline induced cardiotoxicity. Indian J Exp Biol 2016;54:670-5.

47. Muralidharan P, Balamurugan G, Pavan K. Inotropic and cardioprotective effects of Daucus carota Linn. On isoproterenolinduced myocardial infarction. Bangladesh J Pharmacol 2008;3:74-9.

48. Divya H, Parthasarathy A, Mathivanan N, Elangovan V. Desmodium gangeticum root extract attenuates isoproterenol-induced cardiac hypertrophic growth in rats. J Pharm Pharm Res 2014;2:129-37.

49. Jayachandran KS, Vasanthi HR, Rajamanickama GV. Flavonoid rich fraction of Dioscorea bulbifera Linn. (Yam) enhances mitochondrial enzymes and antioxidant status and thereby protects heart from isoproterenol induced myocardial infarction. Curr Pharm Biotechnol
2010;11:887-94

50. Sameer NG, Charu S, Umesh BM, Chandragouda RP, Yogeeta OA, Santosh K, et al. Protective effects of cardamom in isoproterenolinduced myocardial infarction in rats. Int J Mol Sci 2015;16:27457-69.

51. Bhandari U, Ansari MN, Islam F. Cardioprotective effect of aqueous extract of Embelia ribes burm fruits against isoproterenol-induced myocardial infarction in albino rats. Indian J Exp Biol 2008;46:35-40.

52. Ojha S, Golechha M, Kumari S, Arya DS. Protective effect of Emblica officinalis (Amla) on isoproterenol-induced cardiotoxicity in rats. Toxicol Ind Health 2012;28:399-411.

53. Santosh KS, Suman BS, Usha RS, Sayeed A, Ankur M, Manmohan M, et al. Eugenia jambolana pretreatment prevents isoproterenol-induced myocardial damage in rats: Evidence from Biochemical, Molecular, and Histopathological Studies. J Med Food 2014;17:244-53.

54. Anandhi DV, Sowndarya R. Cardioprotective activity of Euphorbia hirta in isoproterenol induced myocardial infarction in rats. J Med Plants Stud 2017:5:330-2.

55. Sudhakumari, Anil KH, Aamir J, Manish J, Muralidhar ST. Cardioprotective effects in methanolic extract of Evolvulus alsinoides Linn on isoproterenol-induced myocardial infarction in albino rats. Int J Basic Med Sci Pharm 2012;2:53-7.

56. Karunakar H, Dhruv KK, Keerthi V. Evaluation of cardioprotective activity of aqueous extract of Garcinia indica Linn fruit rind. Asian J Pharm Clin Res 2015;8:107-12.

57. Ravi M, Padmaja U, Sivanesan S, Sudhakara B. Cardioprotective activity of fruit of Garcinia pedunculata on isoprenaline-induced myocardial infarction in rat. Bangladesh J Pharmacol 2016;11:231-5.

58. Prabha SP, Nitha A, P Ansil PN, Latha MS. Cardioprotective effect of methanolic extract of Gardenia gummifera Linn. F. On isoproterenol induced myocardial infarction in rats. Int J Pharm Sci Res 2014:5:3817-28.

59. Panda VS, N SR. Evaluation of cardioprotective activity of Ginkgo biloba and Ocimum sanctum in rodents. Altern Med Rev 2009;14:161-71.

60. Radhika S, Smila KH, Muthezhilan R. Cardioprotective activity of Hybanthus enneaspermus (Linn.) On isoproterenol induced rats. Indian J Fundam Appl Life Sci 2011;1:90-7.

61. Nagasaraswathi M, Rafi KP, Aleemuddin MA, Gopi CK, Sravania K. Effect of Indigofera tinctoria Linn against isoproterenol induced myocardial infarction on albino wistar rats. J Curr Chem Pharm Sci 2012;3:222-30.

62. Ojha S, Bharti S, Sharma AK, Rani N, Bhatia J, Kumari S, et al. Effect of Inula racemosa root extract on cardiac function and oxidative stress against isoproterenol-induced myocardial infarction. Indian J Biochem Biophys 2011;48:22-8

63. Radhika J, Surya S, Jothi G, Japasheba JL. Cardioprotective role of Justicia traquebareinsis Linn. leaf extract in isoproterenol induced myocardial infarction in albino rats. J Appl Pharm Sci 2013;3:124-8

64. Dianita R, Jantan I, Amran AZ, Jalil J. Protective effects of Labisia pumila var. Alata on biochemical and histopathological alterations of cardiac muscle cells in isoproterenol-induced myocardial infarction rats. Molecules 2015;20:4746-63.

65. Upaganlawar A, Balaraman R. Cardioprotective effects of Lagenaria siceraria fruit juice on isoproterenol-induced myocardial infarction in Wistar rats: A Biochemical and histoarchitecture study. J Young Pharm 2011;3:297-303

66. Ziaee M, Khorrami A, Ebrahimi M, Nourafcan H, Amiraslanzadeh M, Rameshrad M, et al. Cardioprotective effects of essential oil of Lavandula angustifolia on isoproterenol-induced acute myocardial infarction in rat. Iran J Pharm Res 2015;14:279-89.

67. Hasitha DM, Srinivasan D, Sengottuvelu S. Cardioprotective activity of Limonia acidissima against isoproterenol induced myocardial infarction in rats. Res J Pharmtech 2016;9:541-4.

68. Amal D, Kais M, Marwa A, Fatma D, Raouf H, Neji G, et al. Cardioprotective effect of linseed oil against isoproterenolinduced myocardial infarction in Wistar rats: A biochemical and electrocardiographic study. J Physiol Biochem 2015;71:281-8.

69. Yousefi K, Soraya H, Fathiazad F, Khorrami A, Hamedeyazdan S, Maleki-Dizaji N, et al. Cardioprotective effect of methanolic extract of Marrubium vulgare L. On isoproterenol-induced acute myocardial infarction in rats. Indian J Exp Biol 2013;51:653-60.

70. Gomathi R, Vijipriya M, Usha K. Cardioprotective effect of ethanolic extract of Medicago sativa stem on isoproterenol induced myocardial infarction in wistar albino rats. Int J Pharm Pharm Sci 2014;6:839-42.

71. Raish M. Momordica charantia polysaccharides ameliorate oxidative stress, hyperlipidemia, inflammation, and apoptosis during myocardial infarction by inhibiting the NF- $\mathrm{KB}$ signaling pathway. Int J Biol 
Macromol 2017;97:544-51.

72. Koneri R, Balaraman R, Vinoth K, Hariprasad, Ali A. Cardio protective effect of Momordica cymbalaria Fenzl against experimental myocardial injury induced by Isoproterenol. J Clin Diagn Res 2008;2:699-705.

73. Nandave M, Ojha SK, Joshi S, Kumari S, Arya DS. Moringa oleifera leaf extract prevents isoproterenol-induced myocardial damage in rats: Evidence for an antioxidant, antiperoxidative, and cardioprotective intervention. J Med Food 2009;12:47-55.

74. Nade VS, Kawale LA, Bhangale SP, Wale YB. Cardioprotective and antihypertensive potential of Morus alba $\mathrm{L}$. In isoproterenol induced myocardial infarction and renal artery ligation-induced hypertension. J Nat Remed 2013:13:54-67.

75. Nivethetha M, Jayasri J, Brindha P. Effects of Muntingia calabura L. On isoproterenol-induced myocardial infarction. Singapore Med J 2009;50:300-2.

76. Subashini R. Cardioprotective efficacy of Nelumbo nucifera leaf extract on glycoprotein, membrane bound atpase and lysosomal enzymes against isoproterenol induced cardiotoxicity in wistar rats. Int J Pharm Pharm Sci 2014;6:537-41.

77. Al-Taweel AM, Raish M, Perveen S, Fawzy GA, Ahmad A, Ansari MA, et al. Nepeta deflersiana attenuates isoproterenol-induced myocardial injuries in rats: Possible involvement of oxidative stress, apoptosis, inflammation through nuclear factor (NF)- $\mathrm{BB}$ downregulation. Phytomedicine 2017;34:67-75.

78. Gayathri V, Ananthi S, Chandronitha C, Ramakrishnan G, Lakshmisundaram R, Vasanthi HR, et al. Cardioprotective effect of Nerium oleander flower against isoproterenol-induced myocardial oxidative stress in experimental rats. J Cardiovasc Pharmacol Ther 2011;16:96-104.

79. Murugesan M, Ragunath M, Prabu T, Nadanasabapathi S, Sakthivel M, Manju V. Protective role of Black cumin (Nigella sativa) on isoproterenol induced myocardial infarction in rats. Int J Pharmacol Clin Sci 2012;1:45-53.

80. Fathiazad F, Matlobi A, Khorrami A, Hamedeyazdan S, Soraya H, Hammami M, et al. Phytochemical screening and evaluation of cardioprotective activity of ethanolic extract of Ocimum basilicum L. (basil) against isoproterenol induced myocardial infarction in rats. Daru 2012;20:87

81. Saiprasanna B, Manohar BS, Roja YR, Prasanta KC, Rajeshree P. Cardioprotective activity of Ocimum canum hydro-alcoholic leaf extracts against isoproterenol induced myocardial infarction in rats. Res J Pharmacol Pharmacodyn 2012;4:191-201.

82. Ramadan G, El-Beih NM, Arafa NM, Zahra MM. Preventive effects of Egyptian sweet marjoram (Origanum majorana L.) leaves on haematological changes and cardiotoxicity in isoproterenol-treated albino rats. Cardiovasc Toxicol 2013;13:100-9.

83. Abhilash PA, Nisha P, Prathapan A, Nampoothiri SV, Lijo Cherian O, Sunitha TK, et al. Cardioprotective effects of aqueous extract of Oxalis corniculata in experimental myocardial infarction. Exp Toxicol Pathol 2011;63:535-40.

84. Kyu HL, Dukhwan K, Jong-Hoon K. Cardioprotective potential of Korean red ginseng extract on isoproterenol-induced cardiac injury in rats. J Ginseng Res 2013;37:273-82.

85. Kamala KS, Karthikeyan R, Sengottuvelu S. Pandanus odoratissimus: A potential cardioprotective herb against isoproterenol induced myocardial infarction in rats. Sch Acad J Biosci 2016;4:684-7.

86. Adi K, Metowogo K, Mouzou A, Lawson-Evi P, Eklu-Gadegbeku K, Agbonon A, et al. Evaluation of cardioprotective effects of Parkia biglobosa (Jacq. Benth) Mimosaceae stem bark. J Appl Pharm Sci 2013;3:60-4

87. Al-Yahya M, Raish M, AlSaid MS, Ahmad A, Mothana RA, Al-Sohaibani M, et al. 'Ajwa' dates (Phoenix dactylifera L.) extract ameliorates isoproterenol-induced cardiomyopathy through downregulation of oxidative, inflammatory and apoptotic molecules in rodent model. Phytomedicine 2016;23:1240-8.

88. Senthil Kumar SH, Anandan R, Devaki T, Santhosh Kumar M. Cardioprotective effects of Picrorrhiza kurroa against isoproterenolinduced myocardial stress in rats. Fitoterapia 2001;72:402-5.

89. Arya DS, Arora S, Malik S, Nepal S, Kumari S, Ojha S, et al. Effect of Piper betle on cardiac function, marker enzymes, and oxidative stress in isoproterenol-induced cardiotoxicity in rats. Toxicol Mech Methods 2010;20:564-71.

90. Khushbu C, Lalkrishna P, Roshni S, Virendra K, Dhaval M, Timir P. Effect of Piper longum Linn on histopathological and biochemical changes in isoproterenol induced myocardial infarction in rats. Res $\mathrm{J}$ Pharm Biol Chem Sci 2010;1:759-66.

91. Raja S, Ramya I. Cardioprotective potential of methanol extract of
Polygonum glabrum on isoproterenol induced myocardial necrosis in rats. Int J Phytomed 2017;9:518-27.

92. Behera S, Manohar BS, Roja RY, Choudhury PK, Panigrahi R. Cardioprotective effect of Pongamia pinnata hydro-alcoholic leaf extract against isoproterenol induced myocardial infarction in wistar albino rats. Int J Med Pharm Sci 2013;2:1-15.

93. Mahalaxmi M, Pankaj P, Prakash G, Sanjay K. Cardioprotective potential of Punica granatum extract in isoproterenol-induced myocardial infarction in Wistar rats. J Pharmacol Pharmacother 2010;1:32-7

94. Shahat AA, Alsaid MS, Rafatullah S, Al-Sohaibani MO, Parvez MK, Al-Dosari MS, et al. Treatment with Rhus tripartita extract curtails isoproterenol-elicited cardiotoxicity and oxidative stress in rats. BMC Complement Altern Med 2016;16:351.

95. Hu Y, Guo DH, Liu P, Rahman K, Wang DX, Wang B, et al. Antioxidant effects of a Rhodobryum roseum extract and its active components in isoproterenol-induced myocardial injury in rats and cardiac myocytes against oxidative stress-triggered damage. Pharmazie 2009;64:53-7.

96. Manjunatha PM, Sandip K, Divakar G. Preventive effect of Rhododendron arboreum on cardiac markers, lipid peroxides and antioxidants in normal and isoproterenol-induced myocardial necrosis in rats. Afr J Pharm Pharmacol 2011;5:755-63.

97. Geng ZH, Huang L, Song MB, Song YM. Protective effect of a polysaccharide from Salvia miltiorrhiza on isoproterenol (ISO)induced myocardial injury in rats. Carbohydr Polym 2015;132:638-42.

98. Mohamed ST, Lokanath N, Prasanthi A, Madhavi M, Mallika G, Vishnu MN. Aqueous extract of Saussurea lappa root ameliorate oxidative myocardial injury induced by isoproterenol in rats. J Adv Pharm Tech Res 2013;4:94-100.

99. Kosanam N, Rabindra D, Firdous SM. Cardioprotective activity of fruits of Sechium edule. Bangladesh J Pharmacol 2015;10:125-30.

100. Ramadoss S, Kannan K, Balamurugan K, Jeganathan NS, Manavalan R. Efficacy of cardioprotective effects in ethanolic extract of Sida rhombifolia Linn. On isoproterenol-induced myocardial infarction in albino rats. Res J Pharm Biol Chem Sci 2012;3:488-93.

101. Asdaq SM, Chakraborty M. Myocardial potency of Semecarpus anacardium Nut extract against isoproterenol induced myocardial damage in rats. Int J Pharm Sci Rev Res 2010;2:10-3.

102. Aman U, Vaibhav P, Balaraman R. Tomato lycopene attenuates myocardial infarction induced by isoproterenol: Electrocardiographic, biochemical and anti-apoptotic study. Asian Pac J Trop Biomed 2012;2:345-51

103. Sameer AS, Shivaprasad H, Asra F, Preran KH, Syeda JF, Farhath K. Cardio protective effect of Solanum nigrum Linn. in isoproterenol induced myocardial infarction in rat. Sci Technol Arts Res J 2015;4:77-82.

104. Chitikela PP, Dhanunjaya S, Narasimha KG, Pichaiah D, Venkateswarlu M, Ranganayakulu D. Impact of Solanum surettense on membrane bound $\mathrm{Na}+/ \mathrm{K}+$ ATPase and in vivo anti-oxidants activity on isoproterenol induced myocardial injury in rats. J Phytopharmacol 2015:4:139-42.

105. Victor AD, Suresh S, Sowndarya R. Evaluation of cardioprotective activity of Solanum torvum in isoproterenol induced rats. World J Pharm Pharm Sci 2016;5:1633-9.

106. Victor AD, Nancy B, Sowndarya R. Cardioprotective activity of Solanum xanthocarpum in isoproterenol induced myocardial infarction in rats. Int J Pharm Pharm Res 2016;6:371-6.

107. Siddiq A, Shanmukha I, Jyoti TM, Kamlesh G. Cardioprotective effect of Spathodea campanulata bark on isoproterenol-induced myocardial infarction in rats. Asian Pac J Trop Dis 2012;2:S1-5.

108. Akinmoladun AC, Obuotor EM, Barthwal MK, Dikshit M, Farombi EO. Ramipril-like activity of Spondias mombin linn against no-flow ischemia and isoproterenol-induced cardiotoxicity in rat heart. Cardiovasc Toxicol 2010;10:295-305

109. Nabeel K, Manjula SN, Mruthunjaya K, Mahalakshmi AM. Cardio protective effect of Tamarindus indica. Linn against isoproterenol induced myocardial infarction in rats. Int $\mathrm{J}$ Pharm Pharm Sci 2016;8:254-60

110. Shanmukha I, Vijay KM, Ramachandra SS. Cardioprotective effect of hydroalcoholic extract of Tecoma stans flowers against isoproterenol induced myocardial infarction in rats. Asian Pac J Trop Dis 2014;4:S378-84.

111. Sivakumar V, Rajeshkumar S. Screening of cardioprotective effect of Terminalia arjuna Linn. Bark in isoproterenol-Induced myocardial infarction in experimental animals. Int J Pharm Sci Res 2014:5:262-8.

112. Suchalatha S, Shyamala Devi CS. Protective effect of Terminalia chebula against experimental myocardial injury induced by isoproterenol. Indian J Exp Biol 2004;42:174-8. 
113. Shaik AH, Rasool SN, Vikram KR, Abdul KM, Saayi KG, Lakshmi DK. Cardioprotective effect of HPLC standardized ethanolic extract of Terminalia pallida fruits against isoproterenol-induced myocardial infarction in albino rats. J Ethnopharmacol 2012;141:33-40.

114. Alam F, Siddiqui HH. Cardioprotective Activity of Terminelia belerica on isoprenaline induced myocardial necrosis in rat. Asian $\mathrm{J}$ Chem Pharm Res 2014;2:127-36.

115. Neha K, Lubna A. Evaluation of cardioprotective effect of Tinospora cordifolia against isoprenaline induced myocardial infarction in rats. Int J Curr Microbiol Appl Sci 2014;3:543-55.

116. Ipseeta RM, Ujjwala M, Daniel J, Yeswant D. Tribulus terrestris protects rat myocardium against isoproterenol-induced ischemic injury: Role of HSP 70 and cardiac endogenous antioxidants. Alternat Med Stud 2011;1:35-9.

117. Sivanandham V, Selvarani S, Adhithan A. Cardioprotective effect of Trichopus zeylanicus against myocardial ischemia induced by isoproterenol in rats. Bangladesh J Pharmacol 2009;4:88-91

118. Deepika E, Sivakumar V, Selvapriya B, Dinesh K, Mohamed SA. Phytochemical screening and evaluation of cardioprotective activity of ethanolic extract of Trigonella foenum-graecum against isoproterenol induced myocardial infarction rats. Int J Pharm Res Sch 2014;3:146-54.

119. Barman NR, Nandy S, Datta R, Kar PK. Cardioprotective effect of ethanolic extract of Urtica parviflora roxb. Against isoproterenol induced myocardial infarction in rats. Indian $\mathrm{J}$ Pharmacol 2013:45:513-6

120. Mahesh KK, Nelson SK, Rajaram C, Rupesh SK, Ravindra KR. Evaluation of Cardioprotective effect of methanolic extract of Ventilago maderaspatana against isoproterenol induced myocardial infarction in experimental rats. Int J Adv Pharm Res 2012;3:1167-76.

121. Prasad EM, Mopuri R, Islam MS, Kodidhela LD. Cardioprotective effect of Vitex negundo on isoproterenol-induced myocardial necrosis in wistar rats: A dual approach study. Biomed Pharmacother 2017;85:601-10

122. Velavan S, Aegil I, Gokulakrishnan K. Protective effect of Vitis vinifera against myocardial ischemia induced by isoproterenol in rats. Pharmacol Online 2008;3:958-67.

123. Monisha MS, Ragavan B, Rex DA. Cardioprotective potential of Wedelia chinensi on isoproterenol induced myocardial rat. Asian J Biochem 2014;9:98-106.

124. Khalil MI, Ahmmed I, Ahmed R, Tanvir EM, Afroz R, Paul S, et al. Amelioration of isoproterenol-induced oxidative damage in rat myocardium by Withania somnifera leaf extract. Biomed Res Int 2015;2015:624159

125. Amran AZ, Jantan I, Dianita R, Buang F. Protective effects of the standardized extract of Zingiber officinale on myocardium against isoproterenol-induced biochemical and histopathological alterations in rats. Pharm Biol 2015;53:1795-802. 